\title{
Fatty acid composition of freshwater heterotrophic flagellates: an experimental study
}

\author{
Aurélie Véra, Christian Desvilettes" ${ }^{*}$ Alexandre Bec, Gilles Bourdier \\ ${ }^{1}$ Laboratoire de biologie des protistes, UMR CNRS 6023, Université Blaise Pascal, 63177 Aubière Cedex, France
}

\begin{abstract}
The fatty acid compositions of 5 freshwater heterotrophic flagellates were studied using laboratory cultures. The flagellates Bodo saltans, Paraphysomonas vestita, Spumella pudica, Polytoma uvella and Chilomonas paramecium were cultured on Synura medium enriched either with Régilait milk powder (MP medium; Régilait, St Martin Roche, France) or with Tabimin dry fish food (DFF medium; Tetra, Melle, France). The bacteria present in the culture media were also analyzed. The enrichment substrate was found to have a pronounced influence on the fatty acid profiles of the organisms. For example, flagellates grown on the MP medium were characterized by very low contents of polyunsaturated fatty acids (PUFA; 1.28 to $5.50 \%$ of total fatty acids), whereas those grown on DFF medium contained up to $13.20 \%$ PUFA. Irrespective of the species studied, the dominant PUFA were those of the (n-6) series. The presence of branched uneven-numbered fatty acids and of 18:1(n-7) within the protozoans reflects an intensive bacterivorous activity that is understandable in phagotrophic species such as $B$. saltans, $P$. vestita and $S$. pudica but is debatable in C. paramecium and $P$. uvella, as these species have been described as osmotrophic. The heterotrophic flagellates in this study seemed to have varying, but rather limited, capacities of PUFA biosynthesis and bioconversion that were partly related to the physicochemical conditions in the cultures (temperature and dissolved oxygen) and to the phylogenetic relations of the organisms. Species containing a leucoplast or a residual plastid reproduced in a very attenuated manner the characteristic PUFA profiles of autotrophic flagellates belonging to their taxonomic group. This was mainly the case for C. paramecium and P. uvella. Finally, our results suggest that in the natural environment, the PUFA contents of picoplanktonic prey and of dissolved organic matter are the main factors influencing the PUFA content of these flagellates.
\end{abstract}

KEY WORDS: Heterotrophic nanoflagellates · Fatty acids · Microbial loop $\cdot$ PUFA Resale or republication not permitted without written consent of the publisher

\section{INTRODUCTION}

In both marine and freshwater ecosystems, obligate heterotrophic flagellates are known to contribute significantly to the food of mesozooplankton, transferring energy from the microbial loop to higher trophic levels (Stoecker \& McDowell Capuzzo 1990, Burns \& Schallenberg 1996). These protozoans can feed on a large spectrum of particles including small detritus, bacteria, and pico- and nanoplanktonic organisms (Goldman \& Dennet 1990), although some of them can satisfy their energy needs by osmotrophy (Sleigh 2000). This trans-

${ }^{*}$ Corresponding author.

E-mail: christian.desvilettes@univ-bpclermont.fr fer of organic matter from small particles to rotifers or microcrustacea constitutes trophic repackaging and thus makes the fraction of primary production produced by pico- and nanophytoplankton (Gifford 1991) accessible to zooplankton.

However, the predation by metazoans on heterotrophic flagellates can be highly selective (Sanders \& Whickham 1993), perhaps as the content of essential compounds varies greatly from 1 taxonomic group to another (Klein Breteler et al. 1999). Among these compounds, fatty acids (FAs) and especially highly unsaturated FAs are important for the development of zooplankton (Arts 1998). Heterotrophic flagellates may therefore contribute to the trophic transfer of unsaturated FAs, a role that is fulfilled mainly by consumption 
of microalgae (Sargent et al. 1995). Unfortunately, data concerning the FA composition of heterotrophic flagellates are scarce and they suggest that these organisms have different FA synthesis capabilities (Erwin 1973, Wood 1988). At present, we know that the marine heterotrophic dinoflagellate Crypthecodinium cohnii and marine bodonids can produce DHA (22:6, n-3) (Harrington \& Holz 1968, Barclay et al. 1994, Zhukova \& Kharlamenko 1999). For freshwater organisms, information is even more scanty and restricted to the results obtained from batch cultures (Beach et al. 1970). In any case, the absence of any monospecific proliferations of heterotrophic flagellates in lake environments forces the use of laboratory cultures to determine the highly unsaturated FA composition of these protists (Desvilettes et al. 1997).

Furthermore, it has been clearly established that some groups of heterotrophic flagellates are derived from autotrophic plastid-containing forms (Cavalier Smith 2000), so it may be that these heterotrophic forms have inherited the PUFA bioconversion capabilities of autotrophs. Phrased another way: can the concept of taxonomic biomarkers applied to some PUFA that are representative of a given group of autotrophic flagellates (Harrington et al. 1970, Ahlgren et al. 1992, Zhukova \& Aizdaicher 1995) be applied to corresponding obligate heterotroph forms?

The aim of this study was to analyze the FA composition of several free-living obligate heterotrophic flagellates representative of the main freshwater taxonomic groups. We focused on organisms in genera with both autotrophic and heterotrophic forms in lakes. We therefore chose the kinetoplastid Bodo saltans, often associated with particulate organic matter in the water column (Patterson et al. 1993), the chrysomonads Paraphysomonas vestita and Spumella pudica, which are characteristic of freshwater communities (Laybourn Parry \& Parry 2000), and the volvocid Polytoma uvella and the cryptomonad Chilomonas paramecium, which are occasionally abundant in freshwater (Arndt et al. 2000). To determine the influence of the quality of dissolved organic matter on the FA profiles of these protozoans, we used a culture medium enriched in 2 ways.

\section{MATERIALS AND METHODS}

Culture conditions. Flagellate strains were obtained from Culture Collection of Algae and Protozoa (CCAP) (Windermere and Oban, UK) or from our laboratory collection (Bodo saltans and Chilomonas paramecium). Among the tested species, Spumella pudica and Paraphysomonas vestita had a mean diameter of 7 to $8 \mu \mathrm{m}$. The ovoid cells of B. saltans and Polytoma uvella were, respectively, 9 and $15 \mu \mathrm{m}$ long, while the largest species, C. paramecium, was around $35 \mu \mathrm{m}$ long. All the flagellates studied were grown in Synura medium (Provasoli \& Pintner 1960) enriched in one experiment with Régilait milk powder (MP; Régilait, St Martin Roche, France) and in the other with Tabimin dry fish food (DFF; Tetra, Melle, France). The amount of the added nutrient was $0.5 \mathrm{mg} \mathrm{ml}^{-1}$. Each culture was conducted in triplicates in 21 Erlenmeyer flasks filled with $800 \mathrm{ml}$ of Synura medium. Flasks were inoculated with $3 \mathrm{~d}$ old organisms to give an initial density of approximately $10^{3}$ to $10^{4}$ cells $\mathrm{ml}^{-1}$. The cultures were incubated at $20^{\circ} \mathrm{C}$ under a photoperiod of $12: 12 \mathrm{~h}$ light:dark, and they were not shaken or aerated. To characterize the FA composition of the bacteria developing in the flagellate cultures, 2 cultures of bacteria alone were concurrently grown in triplicate in the same Synura medium enriched with MP or DFF.

Flagellates were harvested at the beginning of the stationary phase after 72 to $120 \mathrm{~h}$ of incubation, depending on the species grown. Bacterial cultures were stopped after $4 \mathrm{~d}$ of incubation and harvested.

Sampling. To avoid contamination of the samples with residual nutrients (MP or DFF), the upper $700 \mathrm{ml}$ of the cultures was gently siphoned off into a clean flask, while the bottom layer $(100 \mathrm{ml})$ was discarded. Flagellates were separated from bacteria by centrifugation $(4 \mathrm{~min}$ at $500 \times g$ ) and by washing the phases with Volvic $^{\mathrm{TM}}$ water. Then flagellates were recovered by filtration on pre-combusted GF/F glass-fiber filters. Bacterial contamination of the filters was checked by counting flagellate and bacterial cells in the washed extract of culture before and after filtration. Siphoned cultures of bacteria alone were also filtered on GF/F filters.

Lipid analysis. Lipids were analysed on flagellate filters, bacterial filters and 3 samples of each nutrient (MP and DFF). Total lipids were extracted with chloroform-methanol according to the method of Folch et al. (1957). FA methyl esters were prepared from the lipid extract by hydrolysis in methanolic $\mathrm{NaOH}$ and esterification in methanolic $\mathrm{H}_{2} \mathrm{SO}_{4}$ (Desvilettes et al. 1997). Gas chromatographic analyses were carried out on a Chrompack CP 9001 gas chromatograph equipped with a CP wax 58 column (Varian SA, les Ulis, France) $(25 \times 0.32 \mathrm{~m}$ internal diameter $)$ or with an SPB-1 column (Supelco, Sigma-Aldrich, St Quentin, France) $(30 \times 0.25 \mathrm{~m}$ internal diameter $)$. We used a split-splitless injection system with helium as carrier gas. The oven was programmed to rise from an initial temperature of 160 to $240^{\circ} \mathrm{C}$ at a rate of $2.5^{\circ} \mathrm{C} \mathrm{min}{ }^{-1}$ with the FFAP column. When the SPB-1 column was used, samples were injected at an oven temperature of $150^{\circ} \mathrm{C}$, and after $4 \mathrm{~min}$ the temperature was raised to $250^{\circ} \mathrm{C}$ at a rate of $4^{\circ} \mathrm{C} \mathrm{min}^{-1}$. Individual FA methyl esters were identified by comparing retention times with those 
obtained from Supelco standards and laboratory standards. FA methyl esters were quantified using 23:0 as internal standard added just before derivatization of FAs.

Statistical analysis. The differences for each FA between flagellate species, bacteria and nutrient were tested using a 1-way ANOVA followed by the Scheffé test. The data from analysis of FAs were also subjected to a normalized principal component analysis.

\section{RESULTS}

\section{Flagellate growth}

The growth of flagellate species in the conditions described in materials and methods is shown in Fig. 1. Spumella pudica and Bodo saltans exhibited a similar growth in both nutrient conditions (MP medium and DFF medium). Polytoma uvella failed to grow in DFF medium, while in the same medium, the growth of Chilomonas paramecium and Paraphysomonas vestita was faster than in MP medium. The number of $P$. vestita cells after $96 \mathrm{~h}$ of incubation increased markedly in MP medium by the multiplication of small cell forms (Fig. 1). This observation was followed by a large decrease, which led us to harvest the flagellates. Sudden proliferation of small heterotrophic chrysomonad cells in culture is known to precede strong declines and cyst formation, a phenomenon attributed to the lack of bacterial prey linked to nutrient limitation (Zubkov \& Sleigh 1995).

\section{FA composition of bacteria and nutrient sources (MP and DFF)}

The predominant FAs in the MP medium (Table 1) were saturated $16: 0$ (50.6\% of total), 18:0 (7.06\%) and $14: 0(6.65 \%)$, and monounsaturated 18:1(n-9) $(9.74 \%)$ and $16: 1(n-7)(8.14 \%)$. The major PUFA detected was 18:2(n-6), but the MP substrate lacked long chain PUFA, with the exception of 22:2(n-6). The FA profile of bacteria grown in the MP medium was similar to that of MP (Table 1). The dominant FAs were also saturated 16:0, 18:0 and 14:0, but typical bacterial FAs lacking in the substrate were found in bacteria samples. These FAs were cis-vaccenic FA (18:1n-7, $7.28 \%$ of the total) and branched FAs such as iso and anteiso 15:0 and 17:0 (total amount $>3 \%$, see Table 1).
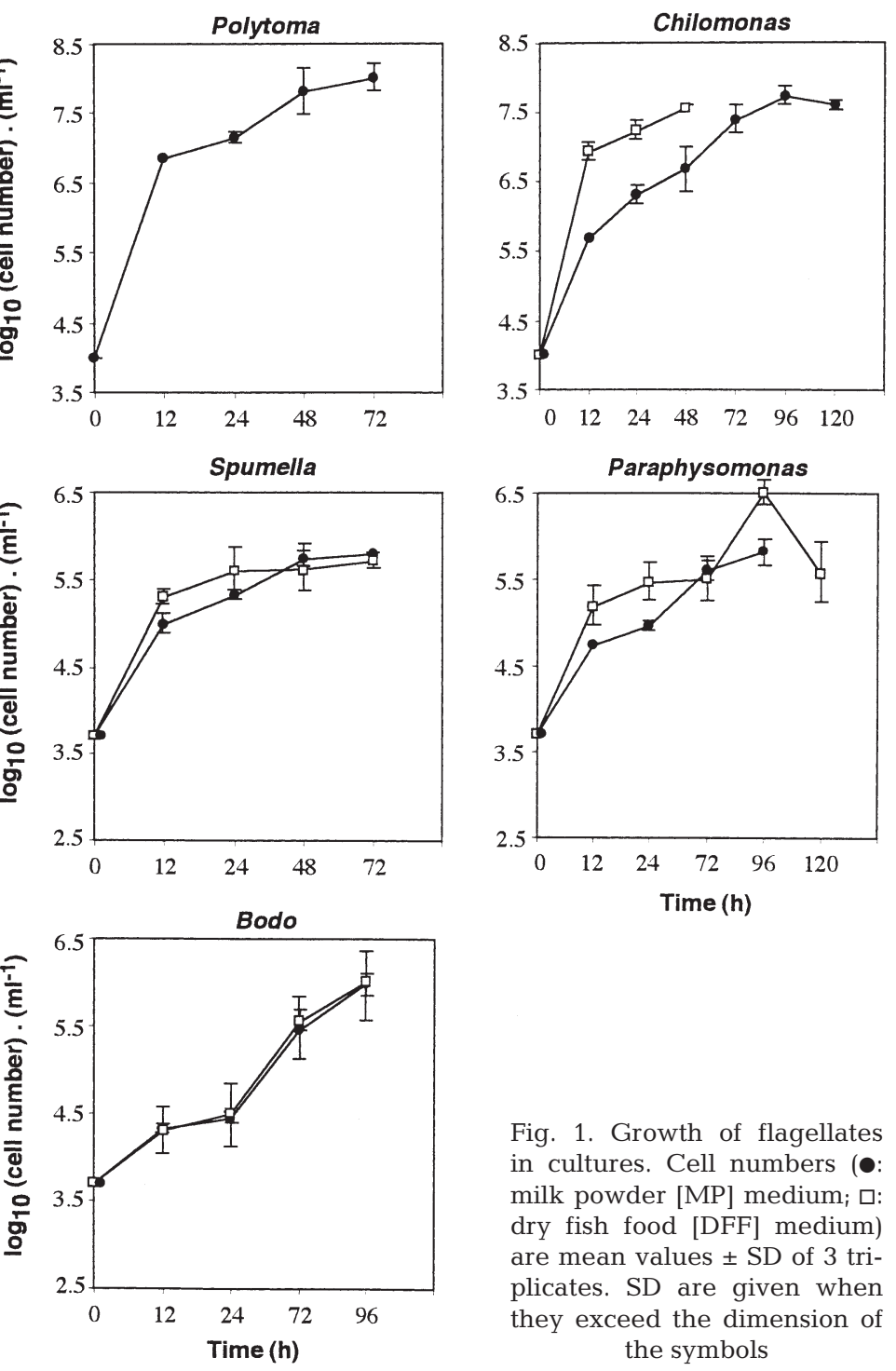

Fig. 1. Growth of flagellates in cultures. Cell numbers (•: milk powder [MP] medium; $\square$ : dry fish food [DFF] medium) are mean values \pm SD of 3 triplicates. SD are given when they exceed the dimension of the symbols

In contrast to MP, the DFF substrate was characterized by high percentages of PUFA $(32.02 \%$ of the total) occurring at concentrations similar to those of saturated FAs (33.50\%; Table 2). These PUFA were dominated by 18:2(n-6) (20.70\%) and 22:6(n-3) $(4.32 \%)$, and to a lesser extent by $18: 3(n-3)$ and 20:5(n-3). Bacteria grown in DFF medium had a quite different composition from those grown in the enrichment substrate (Table 2). The most notable features were the presence of large amounts of branched FAs, making up $23.61 \%$ of total, and the high percentages of $16: 1(n-7)$ and $18: 1(n-7)$. The absence of large amounts of PUFA in these bacteria is also a specific trend, and PUFA were almost exclusively limited to (n-6) acids (3.23\% in total). Finally, there were several significant differences $(p<0.05)$ between bacteria grown in MP medium and bacteria grown in DFF medium (Table 3). This observation concerns dom- 
Table 1. Fatty acid composition (wt \%) of total lipid from flagellates grown in Synura medium enriched with milk powder (MP). Data are weight percentage of total fatty acids and are mean $\pm \mathrm{SD}(\mathrm{n}=3)$. ai: anteiso fatty acids; i: iso fatty acids; MUFA: monounsaturated fatty acids; $n$ : number of culture flasks (bacteria or flagellates) or samples (MP) analyzed; (n-3)/(n-6): ratio of total (n-3) and total (n-6) fatty acids; 'Others' includes components not firmly identified or of a lesser interest: 6:0, 8:0, 10:0 2$\mathrm{OH}$ ?, 12:0 2-OH?, 15:1(n-7), 17:1(n-8)?, 16:2(n-7)?, 18:1(n-5)?, 18:2(n-7), 19:0, 19:1?; PUFA: polyunsaturated fatty acids; $\Sigma(n-3)$ and $\Sigma(\mathrm{n}-6)$ : total fatty acids of $(\mathrm{n}-3)$ and (n-6) series; SAFA: saturated fatty acids; $\Sigma$ Br.FA: sum of branched fatty acids; Tr: traces $<0.2 \%$

\begin{tabular}{|c|c|c|c|c|c|c|c|}
\hline Fatty acids & $\mathrm{MP}$ & Bacteria & $\begin{array}{c}\text { Bodo } \\
\text { saltans }\end{array}$ & $\begin{array}{l}\text { Spumella } \\
\text { pudica }\end{array}$ & $\begin{array}{l}\text { Paraphysomonas } \\
\text { vestita }\end{array}$ & $\begin{array}{c}\text { Polytoma } \\
\text { uvella }\end{array}$ & $\begin{array}{l}\text { Chilomonas } \\
\text { paramecium }\end{array}$ \\
\hline 10:0 & $1.18 \pm 1.16$ & $0.95 \pm 1.00$ & $\operatorname{Tr}$ & $0.38 \pm 0.35$ & $0.80 \pm 0.44$ & $0.93 \pm 0.76$ & $0.63 \pm 0.42$ \\
\hline $12: 0$ & $1.99 \pm 1.88$ & $0.39 \pm 0.23$ & $0.99 \pm 0.18^{\mathrm{a}}$ & $0.96 \pm 0.31$ & $1.68 \pm 0.62$ & $2.38 \pm 0.85^{a}$ & $1.88 \pm 0.69^{\mathrm{a}}$ \\
\hline $13: 0$ & - & $\operatorname{Tr}$ & $\operatorname{Tr}$ & $0.58 \pm 0.30^{a}$ & $2.53 \pm 1.37^{a}$ & $0.39 \pm 0.19$ & $0.59 \pm 0.60$ \\
\hline $14: 0$ & $6.65 \pm 4.19$ & $6.83 \pm 3.81$ & $3.20 \pm 5.54$ & $6.08 \pm 0.76$ & $8.30 \pm 0.01$ & $11.78 \pm 0.98^{\mathrm{a}}$ & $10.32 \pm 2.00$ \\
\hline $15: 0$ & $0.66 \pm 0.68$ & $1.10 \pm 0.58$ & $0.41 \pm 0.70$ & $0.97 \pm 0.02$ & $1.03 \pm 0.01$ & $1.25 \pm 0.01$ & $1.84 \pm 0.27^{a}$ \\
\hline $16: 0$ & $50.60 \pm 29.40$ & $38.27 \pm 19.45$ & $40.54 \pm 3.49$ & $32.86 \pm 3.11$ & $34.91 \pm 0.89$ & $35.35 \pm 1.93$ & $38.64 \pm 5.17$ \\
\hline $17: 0$ & $0.39 \pm 0.22$ & $0.76 \pm 0.31$ & $0.69 \pm 0.25$ & $1.17 \pm 0.70$ & $0.90 \pm 0.15$ & $0.65 \pm 0.10$ & $1.61 \pm 0.60$ \\
\hline $18: 0$ & $7.06 \pm 4.51$ & $9.86 \pm 2.82$ & $10.63 \pm 1.06$ & $7.40 \pm 2.16$ & $7.10 \pm 0.26$ & $8.09 \pm 1.33$ & $7.64 \pm 3.71$ \\
\hline $20: 0$ & $\operatorname{Tr}$ & $0.26 \pm 0.13$ & $\operatorname{Tr}$ & $\operatorname{Tr}$ & $\operatorname{Tr}$ & $0.23 \pm 0.15$ & $0.48 \pm 0.17$ \\
\hline $22: 0$ & $\operatorname{Tr}$ & $\operatorname{Tr}$ & $\operatorname{Tr}$ & $0.25 \pm 0.14$ & $\operatorname{Tr}$ & $\operatorname{Tr}$ & $0.52 \pm 0.52$ \\
\hline $24: 0$ & $\operatorname{Tr}$ & $1.58 \pm 1.04^{b}$ & $\operatorname{Tr}$ & $0.50 \pm 0.70^{a}$ & $0.79 \pm 1.11$ & $\operatorname{Tr}$ & $0.60 \pm 1.04$ \\
\hline i15:0 & $\operatorname{Tr}$ & $0.71 \pm 0.38^{b}$ & $0.53 \pm 0.47$ & $0.78 \pm 0.37$ & $1.31 \pm 0.17$ & $0.39 \pm 0.04$ & $0.43 \pm 0.12$ \\
\hline ai15:0 & $\operatorname{Tr}$ & $0.67 \pm 0.37$ & $1.18 \pm 0.24$ & $0.45 \pm 0.01$ & $0.67 \pm 0.07$ & $0.36 \pm 0.03$ & $0.67 \pm 0.22$ \\
\hline i16:0 & - & $0.27 \pm 0.29$ & $\operatorname{Tr}$ & $0.34 \pm 0.01$ & $0.35 \pm 0.02$ & $0.25 \pm 0.22$ & $0.57 \pm 0.14$ \\
\hline i17:0 & $\operatorname{Tr}$ & $0.55 \pm 0.28$ & $0.52 \pm 0.12$ & $0.64 \pm 0.48$ & $0.25 \pm 0.12$ & $0.36 \pm 0.04$ & $0.50 \pm 0.17$ \\
\hline ai17:0 & $\operatorname{Tr}$ & $0.65 \pm 0.31^{b}$ & $0.87 \pm 0.30$ & $0.43 \pm 0.10^{a}$ & $0.63 \pm 0.04$ & $\operatorname{Tr}$ & $0.69 \pm 0.24$ \\
\hline i18:0 & - & $0.54 \pm 0.31$ & $\operatorname{Tr}$ & - & - & $\operatorname{Tr}$ & - \\
\hline SAFA & 69.07 & 63.38 & 59.56 & 53.80 & 61.25 & 62.41 & 67.62 \\
\hline $14: 1(\mathrm{n}-5)$ & $0.48 \pm 0.41$ & $\operatorname{Tr}$ & $1.52 \pm 0.48$ & $0.41 \pm 0.21$ & $\operatorname{Tr}$ & $0.71 \pm 0.20^{\mathrm{a}}$ & $\operatorname{Tr}$ \\
\hline $16: 1(n-9)$ & $\operatorname{Tr}$ & $3.69 \pm 6.50$ & $2.48 \pm 3.69$ & $5.15 \pm 7.28$ & $0.51 \pm 0.72$ & - & $0.23 \pm 0.39$ \\
\hline $16: 1(n-7)$ & $8.14 \pm 6.45$ & $7.80 \pm 6.14$ & $7.63 \pm 4.42$ & $10.91 \pm 0.88$ & $12.64 \pm 0.42$ & $3.53 \pm 0.15$ & $4.09 \pm 0.83$ \\
\hline $17: 1(\mathrm{n}-7)$ & - & $0.38 \pm 0.28$ & $0.74 \pm 0.42$ & $0.55 \pm 0.77$ & $1.99 \pm 1.04^{\mathrm{a}}$ & $0.44 \pm 0.19$ & $\operatorname{Tr}$ \\
\hline 18:1(n-9) & $9.74 \pm 5.94$ & $5.27 \pm 2.30$ & $8.40 \pm 3.45$ & $7.07 \pm 3.86$ & $6.40 \pm 0.05$ & $13.62 \pm 1.23^{\mathrm{a}}$ & $14.31 \pm 1.90$ \\
\hline $18: 1(n-7)$ & $0.82 \pm 0.59$ & $7.28 \pm 3.86^{\mathrm{b}}$ & $9.40 \pm 2.46$ & $9.20 \pm 0.51$ & $9.38 \pm 0.43$ & $4.33 \pm 0.14$ & $2.61 \pm 1.80$ \\
\hline 20:1(n-9) & $0.24 \pm 0.13$ & $0.21 \pm 0.15$ & $\operatorname{Tr}$ & - & - & $0.34 \pm 0.05$ & $0.38 \pm 0.42$ \\
\hline $24: 1(n-9)$ & - & $0.95 \pm 1.49$ & $\operatorname{Tr}$ & $0.78 \pm 0.84$ & - & - & - \\
\hline MUFA & 19.42 & 25.56 & 30.17 & 34.06 & 30.91 & 23.13 & 21.62 \\
\hline $18: 2(n-6)$ & $3.19 \pm 1.93$ & $0.49 \pm 0.36$ & $2.23 \pm 0.72^{\mathrm{a}}$ & $2.26 \pm 0.09^{a}$ & $1.28 \pm 0.23$ & $2.25 \pm 0.03^{a}$ & $0.67 \pm 0.30$ \\
\hline $18: 3(n-6)$ & $\operatorname{Tr}$ & - & $\operatorname{Tr}$ & $\operatorname{Tr}$ & $\operatorname{Tr}$ & $\operatorname{Tr}$ & $\operatorname{Tr}$ \\
\hline $18: 3(n-3)$ & $0.47 \pm 0.26$ & $\operatorname{Tr}$ & $\mathrm{Tr}$ & _- & $\mathrm{Tr}$ & $0.52 \pm 0.06^{a}$ & $0.29 \pm 0.02^{\mathrm{a}}$ \\
\hline $18: 4(n-3)$ & $\operatorname{Tr}$ & - & - & - & $\operatorname{Tr}$ & $0.31 \pm 0.06^{a}$ & - \\
\hline $20: 2(n-6)$ & $\operatorname{Tr}$ & - & $\operatorname{Tr}$ & - & - & $0.41 \pm 0.50$ & - \\
\hline $20: 3(n-3)$ & - & _- & _ & _- & $\operatorname{Tr}$ & - & $0.50 \pm 0.37$ \\
\hline $20: 5(n-3)$ & $\operatorname{Tr}$ & - & - & $\operatorname{Tr}$ & - & - & $0.72 \pm 0.31^{\mathrm{a}}$ \\
\hline $22: 2(n-6)$ & $0.54 \pm 0.43$ & $0.76 \pm 0.41$ & $0.56 \pm 0.97$ & $2.10 \pm 2.11$ & - & $2.01 \pm 2.89$ & $0.54 \pm 0.57$ \\
\hline PUFA & 4.19 & 1.25 & 3.30 & 4.36 & 1.28 & 5.50 & 2.72 \\
\hline$\Sigma(\mathrm{n}-3)$ & 0.47 & $\operatorname{Tr}$ & $\operatorname{Tr}$ & $\operatorname{Tr}$ & $\operatorname{Tr}$ & 0.83 & 1.51 \\
\hline$\Sigma(\mathrm{n}-6)$ & 3.72 & 1.25 & 2.79 & 4.36 & 1.28 & 4.67 & 1.21 \\
\hline$(n-3) /(n-6)$ & 0.13 & $<0.1$ & $<0.1$ & $<0.1$ & $<0.1$ & 0.17 & 1.25 \\
\hline$\Sigma$ Br.FA & $\operatorname{Tr}$ & 3.39 & 3.10 & 2.65 & 3.21 & 1.36 & 2.87 \\
\hline Others & 5.62 & 8.55 & 5.93 & 6.83 & 5.75 & 7.96 & 7.88 \\
\hline
\end{tabular}

inant saturated FAs such as 14:0, 16:0, 18:0 and branched FAs occurring in higher percentages in DFF bacteria (iso 15:0 and 16:0, anteiso 15:0 and 17:0). Values of 18:2(n-6) and 16:1(n-7) were also significantly different between the 2 bacteria cultures (Table 3; p < 0.05).

\section{FA composition of heterotrophic flagellates}

First, it is important to underline that bacterial contamination of flagellate $\mathrm{GF} / \mathrm{F}$ filters (on a biovolume basis) was around 18.8 to $21.1 \%$ of total biovolume. The highest bacterial contamination (33\%) was esti- 
Table 2. Fatty acid composition (wt \%) of total lipid from flagellates grown in Synura medium enriched with dry fish food (DFF). Data are weight percentages of total fatty acids and are mean \pm SD $(n=3)$. When SD is lacking $n=2$. $n$ : number of culture flasks (or samples in the case of DFF) analysed. Other abbreviations as in Table 1

\begin{tabular}{|c|c|c|c|c|c|c|}
\hline Fatty acids & DFF & Bacteria & B. saltans & S. pudica & $P$. vestita & C. paramecium \\
\hline 10:0 & - & $\operatorname{Tr}$ & 0.50 & $0.65 \pm 0.52$ & $4.07^{\mathrm{a}}$ & $0.90 \pm 0.25^{\mathrm{a}}$ \\
\hline $12: 0$ & $0.54 \pm 0.17$ & $0.22 \pm 0.10$ & $0.53^{\mathrm{a}}$ & $0.82 \pm 0.33$ & 0.33 & $2.79 \pm 1.13^{\mathrm{a}}$ \\
\hline $13: 0$ & $\operatorname{Tr}$ & $0.42 \pm 0.25$ & 2.64 & $0.91 \pm 0.61$ & 0.20 & $0.84 \pm 0.39$ \\
\hline $14: 0$ & $3.70 \pm 0.66$ & $2.42 \pm 0.37^{b}$ & 2.98 & $6.09 \pm 1.50$ & 4.47 & $4.59 \pm 0.64^{\mathrm{a}}$ \\
\hline $15: 0$ & $0.42 \pm 0.06$ & $0.59 \pm 0.07^{b}$ & 0.83 & $0.80 \pm 0.30$ & $0.82^{\mathrm{a}}$ & $0.98 \pm 0.13^{\mathrm{a}}$ \\
\hline $16: 0$ & $20.96 \pm 1.32$ & $18.25 \pm 0.29^{b}$ & $22.67^{\mathrm{a}}$ & $26.93 \pm 4.94^{\mathrm{a}}$ & $26.7^{\mathrm{a}}$ & $26.36 \pm 1.74^{\mathrm{a}}$ \\
\hline $17: 0$ & $0.39 \pm 0.07$ & $0.62 \pm 0.28$ & 0.73 & $0.98 \pm 0,60$ & $5.91^{\mathrm{a}}$ & $0.83 \pm 0.09$ \\
\hline $18: 0$ & $5.34 \pm 0.83$ & $3.14 \pm 0.84^{b}$ & $5.55^{\mathrm{a}}$ & $6.45 \pm 2.24$ & $8.57^{\mathrm{a}}$ & $6.78 \pm 1.15^{\mathrm{a}}$ \\
\hline 20:0 & $0.85 \pm 0.24$ & $0.75 \pm 0.40$ & 0.73 & $0.25 \pm 0.32$ & 0.52 & $0.87 \pm 0.17$ \\
\hline $22: 0$ & $0.50 \pm 0.17$ & $0.63 \pm 0.34$ & 0.53 & $0.30 \pm 0.14$ & 1.05 & $0.46 \pm 0.13$ \\
\hline $24: 0$ & $0.39 \pm 0.23$ & $0.39 \pm 0.29$ & 0.50 & $0.49 \pm 0.70$ & - & $0.95 \pm 1.46 \mathrm{i}$ \\
\hline $15: 0$ & $\operatorname{Tr}$ & $10.24 \pm 0.67^{b}$ & $1.01^{\mathrm{a}}$ & $0.52 \pm 0.37$ & $1.17^{\mathrm{a}}$ & $0.52 \pm 0.16^{\mathrm{a}}$ \\
\hline ai15:0 & - & $4.37 \pm 1.23$ & $1.02^{\mathrm{a}}$ & $0.49 \pm 0.10^{\mathrm{a}}$ & $0.55^{\mathrm{a}}$ & $1.04 \pm 0.52^{\mathrm{a}}$ \\
\hline i16:0 & - & $0.81 \pm 0.15$ & $\operatorname{Tr}$ & $0.33 \pm 0.10^{\mathrm{a}}$ & 0.45 & $0.26 \pm 0.06^{a}$ \\
\hline i17:0 & $0.41 \pm 0.30$ & $3.57 \pm 4.26$ & $0.27^{\mathrm{a}}$ & $0.62 \pm 0.21^{\mathrm{a}}$ & 0.44 & $0.27 \pm 0.02^{\mathrm{a}}$ \\
\hline ai17:0 & - & $4.62 \pm 1.22$ & $0.30^{\mathrm{a}}$ & $0.32 \pm 0.05^{\mathrm{a}}$ & $0.77^{a}$ & $0.28 \pm 0.23^{\mathrm{a}}$ \\
\hline SAFA & 33.50 & 51.03 & 40.79 & 46.95 & 56.03 & 48.72 \\
\hline $14: 1(n-5)$ & - & $\operatorname{Tr}$ & $2.91^{\mathrm{a}}$ & $0.81 \pm 0.61$ & - & $\operatorname{Tr}$ \\
\hline 16:1(n-9) & - & $3.11 \pm 0.96$ & 0.71 & $3.43 \pm 1.94$ & 1.11 & $1.35 \pm 0.37^{a}$ \\
\hline $16: 1(n-7)$ & $5.14 \pm 0.65$ & $17.58 \pm 2.84^{\mathrm{b}}$ & $15.93^{\mathrm{a}}$ & $14.77 \pm 1.64$ & $8.18^{a}$ & $10.46 \pm 5.67$ \\
\hline $17: 1(n-7)$ & $0.31 \pm 0.02$ & $1.97 \pm 0.29^{b}$ & 1.91 & $0.78 \pm 0.60$ & $\operatorname{Tr}$ & $0.27 \pm 0.33$ \\
\hline $18: 1(n-9)$ & $14.96 \pm 1.92$ & $7.26 \pm 0.93^{\mathrm{b}}$ & 9.19 & $9.34 \pm 3.51$ & $12.31^{\mathrm{a}}$ & $8.10 \pm 1.15$ \\
\hline 18:1(n-7) & $2.27 \pm 0.27$ & $6.72 \pm 0.84^{b}$ & 8.90 & $9.57 \pm 0.73^{\mathrm{a}}$ & 8.69 & $8.72 \pm 3.72$ \\
\hline 20:1(n-9) & $3.02 \pm 0.63$ & $0.85 \pm 0.26^{\mathrm{b}}$ & 1.61 & $0.52 \pm 0.49$ & 1.59 & $1.58 \pm 1.38$ \\
\hline $24: 1(n-9)$ & - & $\operatorname{Tr}$ & $\operatorname{Tr}$ & $\operatorname{Tr}$ & - & $0.26 \pm 0.44$ \\
\hline MUFA & 25.70 & 37.48 & 41.16 & 38.70 & 30.77 & 30.73 \\
\hline $18: 2(n-6)$ & $20.70 \pm 1.37$ & $2.86 \pm 0.23^{\mathrm{b}}$ & 4.88 & $4.25 \pm 0.17^{\mathrm{a}}$ & $5.12^{\mathrm{a}}$ & $7.37 \pm 2.62^{\mathrm{a}}$ \\
\hline 18:3(n-6) & $1.31 \pm 0.90$ & - & - & $\operatorname{Tr}$ & - & $0.53 \pm 0.12^{\mathrm{a}}$ \\
\hline $18: 3(n-3)$ & $2.27 \pm 0.18$ & $\operatorname{Tr}$ & $0.44^{\mathrm{a}}$ & $0.37 \pm 0.07^{a}$ & $\operatorname{Tr}$ & $1.67 \pm 0.87^{a}$ \\
\hline $18: 4(n-3)$ & $0.44 \pm 0.03$ & - & 3.76 & $0.84 \pm 0.51$ & 0.32 & $0.58 \pm 0.25$ \\
\hline $20: 2(n-6)$ & $0.80 \pm 0.55$ & $\operatorname{Tr}$ & - & - & - & - \\
\hline $20: 4(n-6)$ & $0.29 \pm 0.04$ & $0.37 \pm 0.63$ & 0.31 & - & - & $0.52 \pm 0.22$ \\
\hline $20: 5(n-3)$ & $1.89 \pm 0.16$ & $\operatorname{Tr}$ & 0.46 & $0.46 \pm 0.37$ & $\operatorname{Tr}$ & $2.53 \pm 1.25^{a}$ \\
\hline $22: 6(n-3)$ & $4.32 \pm 3.63$ & - & - & $0.43 \pm 0.25$ & - & - \\
\hline PUFA & 32.02 & 3.23 & 9.86 & 6.35 & 5.44 & 13.20 \\
\hline$\Sigma(\mathrm{n}-3)$ & 8.91 & $\operatorname{Tr}$ & 4.67 & 2.10 & $\operatorname{Tr}$ & 4.78 \\
\hline$\Sigma(\mathrm{n}-6)$ & 23.11 & 3.23 & 5.19 & 4.25 & 1.28 & 8.41 \\
\hline$(n-3) /(n-6)$ & 0.39 & $<0.1$ & 0.90 & 0.49 & $<0.1$ & 0.57 \\
\hline$\Sigma$ Br.FA & 0.41 & 23.61 & 2.60 & 2.28 & 3.38 & 0.27 \\
\hline Others & 7.80 & 7.38 & 7.19 & 7.41 & 7.12 & 6.75 \\
\hline \multicolumn{7}{|c|}{$\begin{array}{l}\text { a Significant difference between the value of the fatty acid detected in the flagellate and the value of the corresponding fatty } \\
\text { acid detected in bacteria }(1 \text {-way ANOVA; Scheffé test } p<0.05) ; \\
\text { bSignificant difference between the value of the fatty acid detected in bacteria and the value of the corresponding fatty acid } \\
\text { detected in DFF medium }(1 \text {-way ANOVA; Scheffé test } p<0.05)\end{array}$} \\
\hline
\end{tabular}

mated for Polytoma uvella, known to be a strict osmotrophic organism (Sleigh 2000). Fortunately, the yield of total FAs extracted from filters of bacteria incubated alone was $2 \%$ of dry weight in both experimental conditions. As bacteria cell dry weight was substantially lower than that of our flagellate cells (Wood 1988), the proportion of bacterial FAs in flagellate filters was low. We calculated that, on a basis of $10 \%$ FAs (\% dry weight) for flagellate cells, only 3.7 to $6.1 \%$ of the total FAs extracted originated from contaminating bacteria. This of course includes $P$. uvella filters, and the FA amount chosen for the calculation is in good agreement with concentrations reported in protozoans by Beach et al. (1970), Erwin (1973) and Wood (1988) ( 5 to $15 \%$ of the dry weight, $11 \%$ in Chilomonas cells).

The composition of the FA extracted from the flagellates cultivated in MP medium showed several interspecific similarities (Table 1). As in bacteria, the dominant components were saturated and monounsaturated FAs. Saturated compounds ranged from $53.80 \%$ (of total) in Bodo saltans to $67.62 \%$ in Chilomonas paramecium. Monounsaturated FAs made 
Table 3. Statistical analysis of differences in fatty acid composition of bacteria and flagellates grown on MP medium or DFF medium. The differences for each fatty acid of a same species of flagellate or of bacteria were tested between MP medium and DFF medium using a 1-way ANOVA and a Scheffé test. For the same species only the fatty acids that differ significantly are indicated $(\mathrm{p}<0.05)$

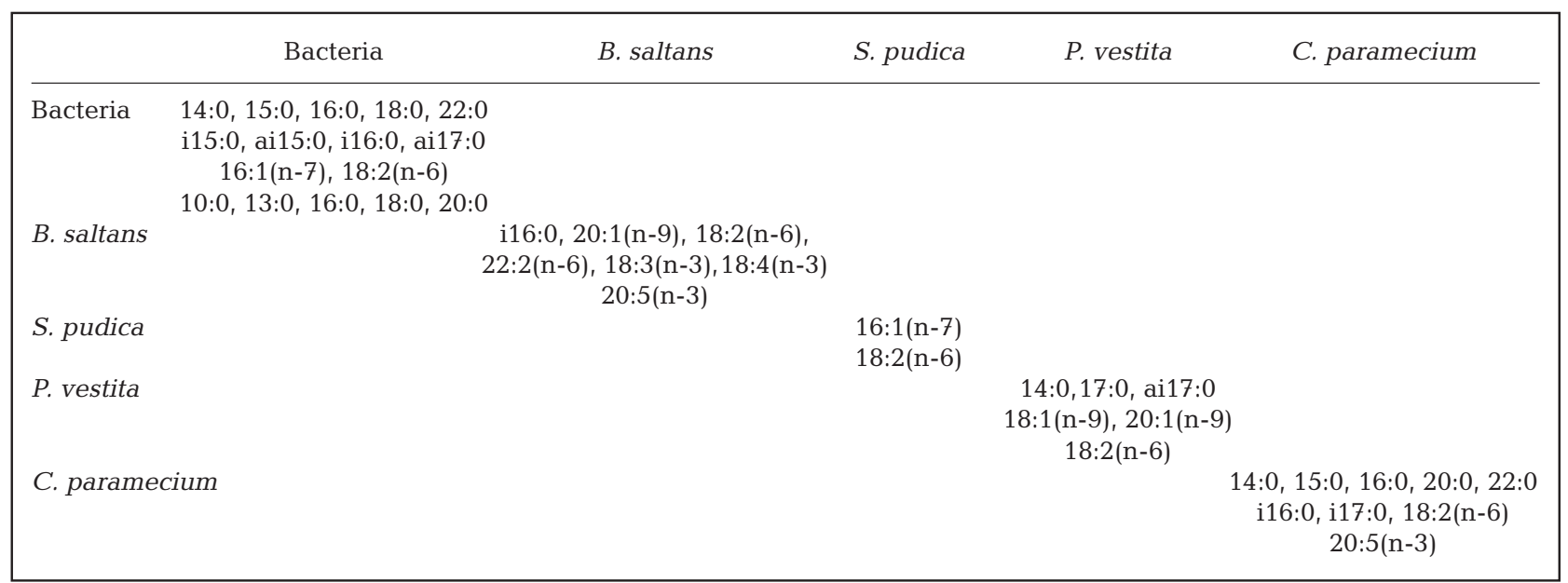

up from 21.62 to $34.06 \%$, depending on the species studied. The major individual FAs belonging to these last 2 categories were on the one hand 16:0, 18:0 and $14: 0$, and on the other hand 16:1(n-7), 18:1(n-7), 18:1(n-9) and 16:1(n-9). All the flagellate species exhibited significant levels of FAs usually characteristic of bacteria. Thus, $1.36 \%$ (Polytoma uvella) to $3.21 \%$ (Paraphysomonas vestita) of branched FAs were detected together with quite high levels of 18:1(n-7) (Table 1). However, this last compound was more abundant in B. saltans, Spumella pudica and P. vestita, with approximately $9.30 \%$ of the total, than in $P$. uvella and C. paramecium. In each flagellate studied the amount of PUFA was low, especially in $P$. vestita and C. paramecium (1.28 to $2.72 \%$ ) and they belonged mainly to (n-6) series with 18:2(n-6) as dominant form. Of special note was the presence of (n-3) acids with 18 carbon atoms in $P$. uvella and with 18 and 20 carbon atoms in C. paramecium, but the detected percentages were very low and ranged from 0.29 to $0.72 \%$ of the total FAs (Table 1).

Except for PUFA, little interspecific variation of the FA profiles was observed in flagellates grown in MP medium. This was confirmed by the principal component analysis, which showed that with the MP substrate, bacteria and flagellates are all grouped together (Fig. 2). On the other hand, intraspecific differences occurred between flagellates tested with both culture conditions (Table 3). This was particularly relevant for saturated FAs (even and branched acids) and 18:2(n-6) $(p<0.05)$. In contrast, the chrysomonads studied showed almost no significant variations (Table 3). However, all the flagellates incubated in DFF medium contained substantial amounts of PUFA, in much higher percentages than in MP medium flagellates
(Tables 1 \& 2). Among these PUFA, (n-3) FAs were important contributors; for instance Bodo saltans contained $3.76 \%$ of $18: 4(n-3)$ and small quantities of 18:3(n-3) and 20:5(n-3). Similarly, Chilomonas paramecium had $2.53 \%$ of $20: 5(n-3)$ and $1.67 \%$ of $18: 3(n-3)$ while the proportion of (n-3) FAs was lower in chrysomonads, especially Paraphysomonas vestita. Finally, it is important to note that, despite the occurrence of (n-3) compounds, 18:2(n-6) was the major PUFA in all the species analyzed (Table 2).

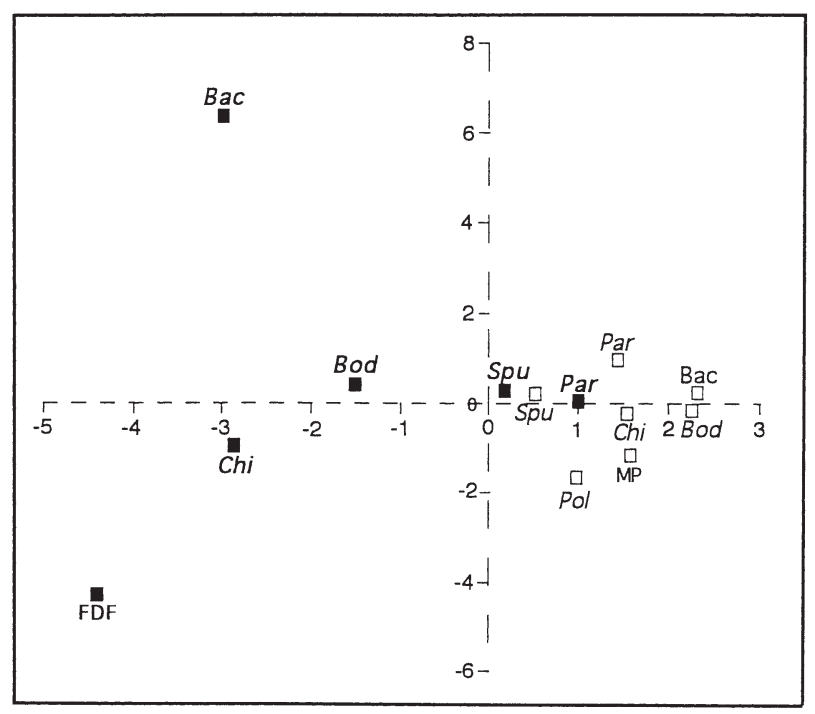

Fig. 2. Principal component plot of fatty acids extracted from flagellates, bacteria, MP and DFF. The analysis is presented for flagellates and bacteria grown on medium enriched with DFF (bold characters, $\square$ ) and medium enriched with MP (口). Bac: bacteria; Bod: Bodo saltans; Chi: Chilomonas paramecium; DFF: dry fish food; MP: milk powder; Par: Paraphysomonas vestita; Pol: Polytoma uvella; Spu: Spumella pudica 
Concerning the other FAs constituting the profiles of the DFF flagellates, saturated FAs were dominated by 16:0, 18:0 and 14:0, while monounsaturated FAs consisted mainly of 16:1(n-7), 18:1(n-9) and 18:1(n-7). From a statistical viewpoint there were more differences between bacteria and flagellates grown in this medium than between bacteria and flagellates grown in MP medium (Table 2). Nevertheless, as observed with MP organisms, all the DFF flagellates also showed typical bacterial FAs (iso and anteiso saturated FAs and 18:1, $\mathrm{n}-7)$. Therefore, it is principally the PUFA composition of DFF substrate, bacteria and flagellate species that determined the statistical variations revealed by principal component analysis. This contrasts markedly with the observations made in the MP medium experiment (Fig. 2). Only DFF Spumella pudica and DFF Paraphysomonas vestita were grouped together, exhibiting great similarities with their corresponding species grown in MP medium (Fig. 2). On the other hand, bacteria, DFF substrate, DFF Chilomonas paramecium and DFF Bodo saltans were largely dispersed (Fig. 2).

\section{DISCUSSION}

The results obtained during this study underline the important effect that organic matter can have on the FA composition of heterotrophic flagellates. An enrichment substrate such as MP had a considerable influence on the FA composition of both bacteria and flagellates But this substrate, which is poor in PUFA, did not favor the occurrence or synthesis of these compounds within flagellates. In contrast, the DFF substrate, which is rich in PUFA, seemed to lead to a considerable PUFA enrichment of the organisms, resulting in heterogeneity in their FA profiles that must have been caused by the specific PUFA metabolisms of each flagellate species.

To some extent FA compositions obtained in the flagellates in this experiment can be compared with published data, although these are few (Wood 1988). For example, authors such as Erwin et al. (1964) and Beach et al. (1970) reported that Chilomonas paramecium cultivated with lactate and thiamine was characterized in terms of its PUFA composition by the occurrence of small quantities of 18:3(n-3), 18:2(n-6) and 20:5(n-3). These findings agree with ours, especially in the MP medium. Similarly, there are few differences between the PUFA compositions of Polytoma uvella grown axenically with acetate (Erwin 1973) and those observed with MP in our experiments. In both cases, this flagellate was characterized by 18:2(n-6) and 18:3(n-6), with low proportions of 18:3(n-3).

The genus Bodo belongs to the kinetoplastids, a group of protozoans that are mainly parasites and that contain mostly PUFA of the (n-6) series (Wood 1988). However,
Zhukova \& Kharlamenko (1999) reported the occurrence of significant percentages of 18:2(n-6), 20:2(n-6) and to a lesser extent 22:6(n-3) in a marine Bodo sp. grown in starch and rice cultures. Our results concerning $B$. saltans therefore showed that there was a very clear dominance of FAs of the (n-6) series and that only $B$. saltans cultivated on the DFF medium also contained FAs of the (n-3) series. In terms of the 2 chrysomonads, the published information concerns autotrophic species that usually contain high quantities of PUFA of (n-3) series and appreciable quantities of (n-6) FA (Ahlgren et al. 1992, Sargent et al. 1995). In our 2 heterotrophic species, Paraphysomonas vestita and Spumella pudica, (n-3) acids were absent from organisms cultivated on the MP medium and occurred in only small quantities in those cultivated on the DFF medium, especially in $P$. vestita.

The occurrence of (n-3) and (n-6) series PUFA and of branched FAs of bacterial type in flagellates could have resulted from a slight contamination of the filters by substrate particles (PUFA) or by bacteria (in the case of iso and anteiso 15:0 and 17:0), but was more probably caused by the mode of nutrition and the PUFA biosynthesis abilities of each species of flagellate. Bodo saltans and species of the genera Paraphysomonas and Spumella are phagotrophic and are therefore able to ingest bacteria and particles of organic matter (Arndt et al. 2000). These particles vary in size; B. saltans feed mainly on bacteria, whereas Paraphysomonas can phagocytose microalgae the same size or larger than itself (Patterson et al. 1993, Arndt et al. 2000). Therefore, the high PUFA content of these 3 flagellates grown in DFF medium may be explained by the ingestion of substrate particles more or less decomposed by bacteria. The presence of branched chain FAs and 18:1(n-7) seems to be directly related to bacterial consumption by these 3 flagellates. Thus, uneven carbon-numbered iso and anteiso FAs and 18:1(n-7) are typical of bacteria from freshwater environments (Scribe et al. 1990, Middelburg et al. 2000). The presence of such compounds in Chilomonas ovata and Polytoma uvella is in principle more difficult to relate to a simple consumption of bacteria. These 2 flagellates are osmotrophic; their energy needs are usually satisfied by simple organic molecules and there is no evidence that they are capable of phagocytosis (Kugrens \& Lee 1991, Sleigh 2000). Therefore, the bacterial FAs detected in them are more probably the result of contamination of the filters, despite the fact that 18:1(n-7) was only half as abundant in these 2 flagellates as in B. saltans, $P$. vestita and $S$. pudica. There are, however, contradictory data that seem to prove the existence of bacterivorous activity in Cryptomonas sp. and other photosynthetic cryptomonads (Roberts \& Laybourn-Parry 1999, Urabe et al. 2000). As the genus Chilomonas is closely related to Campylomonas, a 
photosynthetic genus (Hill 1991), and as vacuoles filled with degenerating ejectisomes have been found in Chilomonas ovata (Kugrens \& Lee 1991), it seems likely that this flagellate can ingest bacteria. But the case for Polytoma uvella is still uncertain. The osmotrophic life-style of C. ovata and P. uvella does, howeve,r make them able to directly assimilate some of the PUFA released into the culture medium by bacterial hydrolysis of the substrates. The assimilation of macromolecules has already been observed in Chilomonas (Sleigh 2000), as has the incorporation of FAs derived from the culture medium in Paramecium aurelia (Kaneishiro et al. 1979).

In all cases, the flagellates in this study were characterized by a very clear dominance of FAs of the (n-6) series (mainly, 18:2,n-6). In the MP medium, only Chilomonas paramecium and Polytoma uvella contained low quantities of (n-3) PUFA. The bioconversion capacities therefore varied among species, to some extent in relation to their phylogenetic origins. For example $P$. uvella contains a degenerate plastid inherited from an ancestral autotrophic form (Gaffal \& Schneider 1980) and Chilomonas ovata contains a leucoplast that lacks thylakoids but where starch is still formed (Kugrens \& Lee 1991). In autotrophic flagellates, most of the 18:2(n-6) and 18:3(n-3) production takes place inside the plastid under the action of membrane-bound $\Delta 12$ and $\Delta 15$ desaturases, the activity of these enzymes being very reduced in the endoplasmic reticular microsomes (Browse \& Somerville 1991, Sato et al. 1997). It is therefore very probable that $C$. ovata and $P$. uvella can still produce 18:2(n-6) and 18:3(n-3) by means of $\Delta 12$ and $\Delta 15$ desaturases that are still functional with the residual plastids. In the heterotrophic tissues (e.g., seed endosperm) of higher plants the leucoplasts are also capable of synthesizing FAs (Eastmond et al. 1997). By conserving these slight bioconversion capacities, C. ovata and $P$. uvella reproduce, in an extremely attenuated manner, the PUFA distribution patterns normally observed in their corresponding autotrophs (Sargent et al. 1995). This explanation seems to be difficult to apply to the chrysomonads Paraphysomonas and Spumella, which contain only a very reduced leucoplast (Belcher \& Swale 1976, Preisig et al. 1991) and which tend to accumulate (n-6) acids. This suggests that the $\Delta 15$ desaturase that occurs in these flagellates is defective, as McConn \& Browse (1996) found that the accumulation of (n-6) FAs with negligible 18:3(n-3) is linked to defective (n-3) $\Delta 15$ desaturase in Arabidopsis thaliana. Among the kinetoplastids, the bodonids are probably the most primitive group (Vickerman 1991). Bodo saltans seems to produce almost entirely 18:2(n-6), a synthesis that in protists unrelated to plastid-containing forms can take place only through the $\Delta 12$ desaturase that occurrs in the microsomal fraction of endoplasmic reticulum (Kaneishiro et al. 1979, Avery et al. 1994).

Finally, all the flagellates studied were distinguished by their low proportions of PUFA, which may have been influenced by the temperature $\left(20^{\circ} \mathrm{C}\right)$ and the absence of shaking in the cultures. A high culture temperature has been reported to result in a lowering of FA desaturation activity in the amoeba Acanthamoeba castellanii (Avery et al. 1994). Similarly, the absence of culture oxygenation in the same amoeba was reflected by a low PUFA content, whereas oxygenation of the cultures led to a 10 -fold increase in $\Delta 12$ desaturase enzyme activity (Avery et al. 1996). However, as long as they are not placed in low-temperature conditions, the low cell PUFA content does not alter the growth of unicellular organisms (Peyou-Ndi et al. 2000).

In conclusion, we found that different heterotrophic flagellates have different PUFA synthesis and bioconversion capacities. These capacities also seem to be limited depending on the physicochemical conditions and are especially effective in the case of (n-6) series PUFA. Furthermore, the quality of the culture enrichment substrates and their PUFA contents have a very strong influence on those of the flagellates. As a result, in the natural environment, the PUFA content of heterotrophic flagellates seems to us to depend mainly on that of the picoplanktonic prey or organic matter that is ingested. Accordingly, the relative intakes by phagotrophy and osmotrophy should play a major role that is worthy of further study, since under the culture conditions used in the present study, heterotrophic flagellates seemed to be too poor in (n-3) series PUFA to be able to sustain major zooplankton growth by themselves.

\section{LITERATURE CITED}

Ahlgren G, Gustafsson I, Boberg M (1992) Fatty acid and chemical composition of freshwater microalgae. J Phycol 28:37-50

Arndt H, Dietrich D, Auer B, Cleven EJ, Gräfenham T, Weitere M, Mylnikov AJ (2000) Functional diversity of heterotrophic flagellates in aquatic ecosystems. In: Leadbeater BSC, Green JC (eds) The flagellates, unity diversity and evolution. Taylor \& Francis Ltd, London, p 240-269

Arts MT (1998) Lipids in freshwater zooplankton:selected ecological and physiological aspects. In: Arts MT, Wainman BC (eds) Lipids in freshwater ecosystems. SpringerVerlag, New York, p 71-86

Avery SV, Lloyd D, Harwood J (1994) Changes in membrane fatty acid composition and delta12-desaturase activity during growth of Acanthamoeba castellanii in batch culture. J Eukaryot Microbiol 41:396-401

Avery SV, Harwood J, Rutter AJ, Lloyd D (1996) Oxygen dependent low-temperature composition and delta12 (n-6)-desaturase induction and alteration of fatty acid composition in Acanthamoeba castellanii in batch culture. Microbiology 142:2213-2221

Barclay WR, Meager KM, Abril JR (1994) Heterotrophic production of long chain omega-3 fatty acids utilizing algae 
and algae-like organisms. J Appl Phycol 6:123-129

Beach DH, Harrington GW, Holz GG (1970) The polyunsaturated fatty acids of marine and freshwater cryptomonads. J Protozool 17:501-510

Belcher JH, Swale EMF (1976) Spumella elongata (Stokes) nov. comb., a colourless flagellate from soil. Arch Protistenkd 118:215-220

Browse J, Somerville C (1991) Glycerolipids synthesis: biochemistry and regulation. Annu Rev Plant Physiol Mol Biol 42:467-506

Burns CW, Schallenberg M (1996) Relative impacts of copepods, cladocerans and nutrients on the microbial food web of a mesotrophic lake. J Plankton Res 15:683-714

Cavalier Smith T (2000) Flagellate megaevolution: the basis for eukaryote diversification. In: Leadbeater BSC, Green JC (eds) The flagellates, unity diversity and evolution. Taylor \& Francis Ltd, London, p 361-391

Desvilettes C, Bourdier G, Amblard C, Barth B (1997) Use of fatty acids for the assessment of zooplankton grazing on bacteria, protozoans and microalgae. Freshw Biol 38: 629-637

Eastmond PJ, Dennis DT, Rawsthorne S (1997) Evidence that a malate/inorganic phosphate exchange translocator import carbon across the leucoplast envelope of a fatty acid synthesis in developing castor seed endosperm. Plant Physiol 114:851-856

Erwin JA (1973) Lipids and biomembranes of eukaryotic microorganisms. In: Erwin JA (ed) Comparative biochemistry of fatty acids in eukaryotic microorganisms. Academic Press, New York, p 41-143

Erwin JA, Hulanicka D, Bloch K (1964) Comparative aspect of unsaturated fatty acids synthesis. Comp Biochem Physiol 12:191-207

Folch JM, Less M, Stanley GH (1957) A simple method for the isolation and purification of total lipids from animal tissues. J Biol Chem 226:497-509

Gaffal KP, Schneider GJ (1980) Morphogenesis of the plastidome and flagellar apparatus during the vegetative life cycle of the colorless phytoflagellate Polytoma papillatum. Cytobios 105:43-61

Gifford DJ (1991) The protozoan-metazoan trophic link in pelagic ecosystems. J Protozool 38:81-86

Goldman JC, Dennet MR (1990) Dynamics of prey selection by an omnivorous flagellate. Mar Ecol Prog Ser 59:183-194

Harrington GW, Holz GG (1968) The monoenoic and docosahexaenoic fatty acids of a heterotrophic dinoflagellate. Biochim Biophys Acta 164:137-139

Harrington GW, Beach DH, Dunham JE, Holz GG (1970) The polyunsaturated fatty acids of marine dinoflagellate. J Protozool 17:213-219

Hill DRA (1991) Diversity of heterotrophic cryptomonads. In: Patterson DJ, Larsen J (eds) The biology of free-living heterotrophic flagellates. The systematics association. Clarendon Press, Oxford, p 235-241

Kaneishiro ES, Beischel LS, Merkel SJ, Rhoads DL (1979) The fatty acid composition of Paramecium aurelia cells and cilia: changes with culture age. J Protozool 26:147-158

Klein Breteler WCM, Schogt N, Baas M, Schouten S, Kraay GW (1999) Trophic upgrading of food quality by protozoans enhancing copepod growth: role of essential lipids. Mar Biol 135:191-198

Kugrens P, Lee RE (1991) Organization of cryptomonads. In: Patterson DJ, Larsen J (eds) The biology of free-living heterotrophic flagellates. The systematics association. Clarendon Press, Oxford, p 219-235

Laybourn Parry J, Parry J (2000) Flagellates and the microbial loop. In: Leadbeater BSC, Green JC (eds) The flagellates, unity diversity and evolution. Taylor \& Francis Ltd, Lon- don, p 216-240

McConn M, Browse J (1996) The critical requirement for linolenic acid is pollen development, not photosynthesis, in an Arabidopsis mutant. Plant Cell 8:403-416

Middelburg JJ, Barranguet C, Boschker HTS, Herman PMJ, Moens T, Heip CHR (2000) The fate of interdidal microphytobenthos carbon: an in situ ${ }^{13} \mathrm{C}$-labeling study. Limnol Oceanogr 45:1224-1234

Patterson DJ, Nygaard K, Steinberg G, Turley CM (1993) Heterotrophic flagellates and other protists associated with oceanic detritus throughout the water column in the mid North Atlantic. J Mar Biol Assoc UK 73:67-95

Peyou-Ndi MM, Watts JL, Browse J (2000) Identification and characterization of an animal $\Delta 12$ fatty acid desaturase gene by heterologous expression in Saccharomyces cerevisiae. Arch Biochem Biophys 15:399-408

Preisig HR, Vors N, Hällfors G (1991) Diversity of heterotrophic heterokont flagellates. In: Patterson DJ, Larsen J (eds) The biology of free-living heterotrophic flagellates. The systematics association. Clarendon Press, Oxford, p 361-401

Provasoli L, Pintner IS (1960) Artificial media for freshwater algae. In: Tryon CA, Hatmann RT (eds) The ecology of algae. Pymatuning Symposia, p 84-86

Roberts E, Laybourn-Parry J (1999) Mixotrophic chrysophytes and their predators in the Dry Valley Lakes of Antarctica. Freshw Biol 41:737-746

Sanders RW, Whickham SA (1993) Planktonic protozoa and metazoa predation, food quality and population control. Mar Microb Food Webs 7:197-223

Sargent JR, Bell MV, Henderson RJ (1995) Protists as source of (n-3) polyunsaturated fatty acids for vertebrate development. In: Brugerolle G, Mignot JP (eds) Protistological actualities. Proc 2nd Eur Cong Protistol. Université Blaise Pascal, Clermont-Ferrand, p 54-64

Sato N, Fujiwara S, Kawaguchi A, Tsuzuki M (1997) Cloning a gene for chloroplast $\omega 6$ desaturase of a green alga Chlamydomonas reihardtii. J Biochem 122:1224-1232

Scribe P, Ngoumbi-Nzouzi JS, Fuché C, Pèpe C, Saliot A (1990) Biogeochemistry of organic matter in lake Geneva. I. Particulate hydrocarbons as biogenic and antropogenic molecular markers. Hydrobiologia 207:319-331

Sleigh MA (2000) Trophic strategies. In: Leadbeater BSC, Green JC (eds) The flagellates, unity diversity and evolution. Taylor \& Francis Ltd, London, p 147-166

Stoecker DK, McDowell Capuzzo J (1990) Predation on protozoa: its importance to zooplankton. J Plankton Res 12: 891-908

Urabe J, Bahadur Gurung T, Yoshida T, Sekino T, Nakanishi M (2000) Diel changes in phagotrophy by Cryptomonas in lake Biwa. Limnol Oceanogr 45:1558-1563

Vickerman L (1991) Organization of the Bodonid flagellates. In: Patterson DJ, Larsen J (eds) The biology of free-living heterotrophic flagellates. The systematics association. Clarendon Press, Oxford, p 159-176

Wood BJB (1988) Lipids of algae and protozoa. In: Ratledge C, Wilkinson SG (eds) Microbial lipids. Academic Press, London, p 806-867

Zhukova NV, Aizdaicher NA (1995) Fatty acid composition of 15 species of marine microalgae. Phytochemistry 39:351-356

Zhukova NV, Kharlamenko VI (1999) Sources of essential fatty acids in the marine microbial loop. Aquat Microb Ecol 17:153-157

Zubkov MV, Sleigh MA (1995) Bacterivory by starved marine heterotrophic nanoflagellates of two species that feed differently, estimated uptake of dual radioactive-labelled bacteria. FEMS Microbiol Ecol 17:57-66 